\title{
Comparison of maternal outcome in patients treated with methyldopa and labetalol in the management of hypertensive disorders of pregnancy
}

\author{
Harish K. M. ${ }^{1 *}$, Shwetha N. ${ }^{1}$, Dipankar Debnath ${ }^{2}$
}

\author{
${ }^{1}$ Department of Obstetrics and Gynecology, Malabar Medical College, Calicut, Kerala, India \\ ${ }^{2}$ Department of Obstetrics and Gynecology, Regional Institute of Medical Sciences, Imphal, Manipur, India
}

Received: 14 April 2018

Accepted: 01 May 2018

\section{*Correspondence:}

Dr. Harish KM,

E-mail:kmharish07@gmail.com

Copyright: $\odot$ the author(s), publisher and licensee Medip Academy. This is an open-access article distributed under the terms of the Creative Commons Attribution Non-Commercial License, which permits unrestricted non-commercial use, distribution, and reproduction in any medium, provided the original work is properly cited.

\begin{abstract}
Background: To compare the maternal outcome in patients treated with methyldopa and labetalol in the management of moderate to severe hypertensive disorders of pregnancy (HDP).

Methods: The present study is Prospective parallel group comparative study on 200 out-patients and inpatients selected between January 2013 to December 2013 from OPD and antenatal ward of Obstetrics and Gynaecology department, of tertiary care teaching hospital, Regional Institute of Medical Sciences, Imphal. 100 patients each were distributed to methyldopa group and labetalol group respectively.

Results: There was statistically significant reduction in the mean systolic BP + Standard deviation / Diastolic BP + Standard deviation and Mean arterial pressure (MAP) in Labetalol group (from $156.84+5.75 / 100.20+6.02 \mathrm{mmHg}$ and $119.08+4.07$ to $133.76+3.50 / 85.14+3.98 \mathrm{mmHg}$ and $101.35+2.94$ ) compared to Methyldopa group (from $156.00+6.581 / 100.96+6.896 \mathrm{mmHg}$ and $119.30+4.86$ to $137.20+2.36 / 89.02+2.38 \mathrm{mmHg}$ and $105.08+1.78)$. Risk of adverse effects was less in Labetalol group (12\%) but complication during pregnancy was more in Methyldopa group (51\%). Number of spontaneous onset of labour and vaginal mode of delivery was more in Labetalol group.

Conclusions: The present study shows that primiparity, residing in rural area, with low income group and overweight are at high risk of developing Hypertensive Disorders of Pregnancy. Labetalol is the better drug in controlling blood pressure with less adverse effects and maternal complication.
\end{abstract}

Keywords: Hypertensive disorders of pregnancy, Labetalol, Methyldopa

\section{INTRODUCTION}

Hypertensive disorder of pregnancy is an idiopathic multisystem disorder of pregnancy characterised by proteinuric or non-proteinuric hypertension. Hypertension complicates 6-12\% of all pregnancies.

Although the overwhelming majority of the affected will have successful pregnancy outcome, the condition can give rise to severe multisystem complication including cerebral haemorrhage hepatic and renal dysfunction and respiratory compromise. ${ }^{1}$ Recent estimate indicates that over 63000 women die worldwide each year because of
Hypertensive disorders of pregnancy complications and $98 \%$ of these occurring in developing countries. Hypertensive disorders of pregnancy include two relatively benign conditions (chronic and gestational hypertension) and the more severe condition of preeclampsia and eclampsia. Pre-eclampsia/ eclampsia constitute $70 \%$ and chronic hypertension 30\%. The incidence of eclampsia is one in 100 to 1 in 2000 pregnancies. $^{2}$

The Working group classification of hypertensive disorders complicating pregnancy describes four types of hypertensive disease. ${ }^{3}$ 
- Gestational Hypertension.

- Pre-eclampsia.

- Eclampsia.

- Superimposed pre-eclampsia on chronic hypertension.

- Chronic Hypertension.

Hypertension in pregnancy is diagnosed empirically when appropriately taken blood pressure exceeds systolic $140 \mathrm{mmHg}$ and diastolic $90 \mathrm{mmHg}$. In normal pregnancy systolic blood pressure changes little; however, diastolic pressure decreases by an average of $10 \mathrm{mmHg}$ early in gestation (13 to 20 weeks) and rise again to prepregnancy level in third trimester. ${ }^{4}$

First line agents for moderate and severe hypertension are methyldopa and labetalol. The aim of antihypertensive therapy is to achieve blood pressure lower than 160/110 $\mathrm{mm} \mathrm{Hg}$ but not lower than $130 / 90 \mathrm{mmHg}$ without compromising uteroplacental blood flow and placental perfusion. ${ }^{5}$

Treating hypertension during pregnancy is a real challenge. Opinion differs as to which is the best antihypertensive agent during pregnancy. While the goal of treatment is to reduce maternal risk, agents selected must be efficacious. ${ }^{6}$

\section{METHODS}

The present study is a hospital based prospective parallel group comparative study of patients in Obstetrics and Gynaecology department of tertiary care teaching hospital, Regional Institute of Medical Sciences, Imphal. Data collection will be over a period of one calendar year i.e. from January 2013 to December 2013.

Hypertensive disorders of pregnancy will be diagnosed when blood pressure measurement shows systolic BP of $140 \mathrm{mmHg}$ and above or diastolic BP of $90 \mathrm{mmHg}$ and above, measured on two occasion 6hours apart. The severity of hypertension in terms of systolic/diastolic pressure was classified as mild (140-149/90-99 mmHg), moderate (150-159/100-109 $\mathrm{mmHg})$ or severe (>160/110mmHg). Blood pressure will be recorded using Mercury Spygmomanometer with patient in 15 degrees left lateral recumbent position.

Steps involved in BP measurement using the auscultatory technique includes use of the correct-sized cuff, initial inflation of the cuff $20-30 \mathrm{mmHg}$ above the palpable systolic BP, deflation at a rate of $2 \mathrm{mmHg}$ per second, recording $\mathrm{BP}$ to the nearest $2 \mathrm{mmHg}$ and use of Korotkoff phase V to indicate diastolic BP.

Cases of women with moderate to severe hypertensive disorder of pregnancy will be included in the study. Patients who are in labour, critically ill, presenting with eclampsia, HELLP syndrome, heart disease, liver disease will be excluded from the study. Written consent from the patients will be taken before including in the study.

After clinical examination, patients with Hypertensive disorders of pregnancy will be offered with integrated package of care covering admission to hospital, treatment, measurement of blood pressure, testing for proteinuria and blood tests.

Urine protein will be checked by automated reagent-strip reading device and patients are classified as proteinuric and non-proteinuric Hypertensive disorders of pregnancy.

The patient for the study will be selected randomly and using computer generated sequence of random numbers and distributed to either of the two-treatment arm Labetalol or Methyldopa. Both protenuric and nonproteinuric Hypertensive disorders of pregnancy patients are equally distributed into two treatment arms.

Patients with moderate Hypertensive disorders of pregnancy will be given either labetalol $200 \mathrm{mg}$ or methyldopa $750 \mathrm{mg}$ daily in divided doses. This dose will be doubled 3 days later if satisfactory BP control had not occurred. Maximum dose for labetalol is $1200 \mathrm{mg} /$ day and for methyldopa is $3 \mathrm{gms} /$ day.

BP control will be considered satisfactory if two of three consecutive readings of MAP were less than $105 \mathrm{mmHg}$. Patients with severe hypertension will be initially treated with intravenous labetalol to stabilize the blood pressure in the range of systolic $130-150 \mathrm{mmHg}$ and diastolic 85 $100 \mathrm{mmHg}$, there after patients will be equally distributed into two treatment arms.

Women with moderate gestational hypertension will be managed as outpatient with twice weekly BP monitoring. Severe gestational hypertensive patient and moderate to severe pre-eclampsia patients will be managed as inpatients with 4 times/day BP monitoring.

BP monitoring is done till the time of termination of pregnancy. The results are pooled to determine average systolic/diastolic and mean arterial pressure. Time and mode of termination of pregnancy will be done as per NICE clinical guidelines No. 107 and obstetric indication. $^{7}$

Following parameters will be documented during the time of the study:

- Blood pressure (systolic/diastolic and mean arterial pressure) before commencement of anti-hypertensive treatment.

- Socio-demographic profile of patients such as marital status, educational status, occupation, religion and habitant.

- Characteristic of patients under study such as Age, BMI, Parity and Period of gestation. 
Types of outcome measured are

- Average blood pressure during anti-hypertensive therapy

- Adverse effects of labetalol and methyldopa.

- Progression to pre-eclampsia and eclampsia, Obstetric and systemic complication.

- Mode of onset of labour and mode of delivery.

Statistical calculation is done by paired and unpaired ttest, chi-square test using SPSS software version 16. Results of blood pressure will be expressed as mean + standard deviation. The significance of differences between means will be determined using student's t test (BPs). P <0.05 will be considered as significant.

\section{RESULTS}

Present study shows that 200 patients were detected to have moderate $(150 / 100$ to $159 / 109 \mathrm{mmHg})$ to severe (160/110 $\mathrm{mmHg}$ and above) hypertensive disorder of pregnancy, among these 180 had non-proteinuric and 20 had proteinuric hypertension. 100 each (90 nonproteinuric and 10 proteinuric Hypertensive disorders of pregnancy) were distributed randomly using computer generated sequence of random numbers to either of the two-treatment arms labetalol or methyldopa. Table 1 shows socio-demographic profile of patients. Majority of the patients with Hypertensive disorders of pregnancy in present study were married $(99 \%)$, house wife $(87 \%)$ by occupation, studied up to graduation (49\%), Hindu (45\%) by religion, residing in rural $(70 \%)$ area and belong to medium income $(72 \%)$ group.

Table 1: Socio-demographic profile.

\begin{tabular}{|c|c|c|c|}
\hline \multicolumn{2}{|c|}{ Socio-demographic profile } & No. & $\%$ \\
\hline \multirow{3}{*}{ Marital status } & Unmarried & 2 & 1 \\
\hline & Married & 198 & 99 \\
\hline & Total & 200 & 100 \\
\hline \multirow{6}{*}{ Educational status } & Illiterate & 02 & 1 \\
\hline & Undermetric & 18 & 9 \\
\hline & Metric & 38 & 19 \\
\hline & Intermediate & 44 & 22 \\
\hline & Graduate & 98 & 49 \\
\hline & Total & 200 & 100 \\
\hline \multirow{4}{*}{ Occupation } & Unemployed & 2 & 1 \\
\hline & Student & 24 & 12 \\
\hline & Housewife & 174 & 87 \\
\hline & Total & 200 & 100 \\
\hline \multirow{4}{*}{ Religion } & Hindu & 90 & 45 \\
\hline & Muslim & 86 & 43 \\
\hline & Christian & 24 & 12 \\
\hline & Total & 200 & 100 \\
\hline \multirow{3}{*}{ Habitant } & Urban & 60 & 30 \\
\hline & Rural & 140 & 70 \\
\hline & Total & 200 & 100 \\
\hline \multirow{3}{*}{ Socioeconomic state } & Low & 56 & 28 \\
\hline & Medium & 144 & 72 \\
\hline & Total & 200 & 100 \\
\hline
\end{tabular}

Table 2 indicates that more number of patients were in the age group between 20 to 24 yrs (64\%) and overweight patients were $60 \%$.

Majority of patients were Primiparous (48\%) and between 33 to 37 weeks of pregnancy $(85 \%)$.

Table 2: Characteristics of patients.

\begin{tabular}{|c|c|c|c|}
\hline \multicolumn{2}{|c|}{ Characteristics of patients } & No & $\%$ \\
\hline \multirow{5}{*}{ Age } & $<19$ years & 4 & 2 \\
\hline & 20-24 years & 128 & 64 \\
\hline & 25-29years & 20 & 10 \\
\hline & 30 years and above & 28 & 14 \\
\hline & Total & 200 & 100 \\
\hline \multirow[t]{5}{*}{ BMI in $\mathrm{kg} / \mathrm{m}^{2}$} & $<18$ & 8 & 4 \\
\hline & $18-24.9$ & 88 & 44 \\
\hline & $25-29.9$ & 98 & 49 \\
\hline & $>30$ & 6 & 3 \\
\hline & Total & 200 & 100 \\
\hline \multirow{4}{*}{ Parity } & $\mathrm{P}_{0+0}$ & 96 & 48 \\
\hline & $\mathrm{P}_{1+0}$ & 68 & 34 \\
\hline & $\mathrm{P}_{2}$ and above & 36 & 18 \\
\hline & Total & 200 & 100 \\
\hline \multirow{4}{*}{$\begin{array}{l}\text { Period of } \\
\text { gestation }\end{array}$} & 28-32 weeks & 20 & 10 \\
\hline & 33-37 weeks & 170 & 85 \\
\hline & $38-40$ weeks & 10 & 5 \\
\hline & Total & 200 & 100 \\
\hline
\end{tabular}

Table 3 shows that there is no statistically significant difference between labetalol and methyldopa in systolic $\mathrm{BP}$ (with $\mathrm{p}$ value 0.337 ), diastolic BP ( $\mathrm{p}$ value 0.403 ) and MAP ( $p$ value 0.729 ) before the commencement of treatment.

There was statistically significant reduction in the mean systolic BP + Standard deviation / Diastolic BP + Standard deviation in Labetalol group (from $156.84+$ $5.75 / 100.20+6.02 \mathrm{mmHg}$ to $133.76 \pm 3.50 / 85.14 \pm 3.98$ $\mathrm{mmHg}$ ) compared to Methyldopa group (from $156.00+$ $6.581 / 100.96+6.89 \mathrm{mmHg}$ to $137.20+2.36 / 89.02+$ $2.38 \mathrm{mmHg}$ ). Mean arterial pressure (MAP) reduction was more in Labetalol group (from $119.08+4.07$ to 101.35+2.94) than Methyldopa group (from $119.30+$ 4.86 to $105.08+1.78$ ).

Table 4 shows that risk of adverse effects due to drugs were more in patients who received Methyldopa (18\%) in relation to the patients who received Labetalol (12\%). Minor side effects were common in labetalol group. Even though adverse effects were more in the methyldopa group, $\mathrm{p}$ value is 0.322 shows no statistical significant difference.

Table 5 shows that $57 \%$ in labetalol group and $49 \%$ in methyldopa group had no complications. Among 90 patients in each group who had non-proteinuric hypertension, 26 patients in methyldopa group and 22 patients in labetalol group progressed to proteinuric 
Hypertensive disorders of pregnancy. Obstetric and systemic complications were $28 \%$ and $3 \%$ respectively in labetalol group where as $33 \%$ and $5 \%$ respectively in
Methyldopa group. Increase in risk of pregnancy complication in methyldopa group is statistically not significant with $\mathrm{p}$ value 0.322 .

Table 3: Evaluation of Blood pressure.

\begin{tabular}{|llll|}
\hline Blood Pressure & Before treatment & During treatment & P value \\
\hline Systolic BP mmHg & & $133.76 \pm 3.50$ & $<0.001$ \\
\hline Labetalol Group & $156.84 \pm 5.75$ & $137.20 \pm 2.36$ & $<0.001$ \\
\hline Methyldopa Group & $156.00 \pm 6.58$ & 0.001 & - \\
\hline P value & 0.337 & & $<0.001$ \\
\hline Diastolic BP mmHg & & $85.14 \pm 3.98$ & $<0.001$ \\
\hline Labetalol Group & $100.20 \pm 6.02$ & $89.02 \pm 2.38$ & - \\
\hline Methyldopa Group & $100.96 \pm 6.89$ & 0.0001 & $<0.001$ \\
\hline P value & 0.4037 & & $<0.001$ \\
\hline MAP Rx & & $101.35 \pm 2.94$ & - \\
\hline Labetalol Group & $119.08 \pm 4.07$ & $105.08 \pm 1.78$ & 0.0001 \\
\hline Methyldopa Group & $119.30 \pm 4.86$ & 0.7290 & \\
\hline P value & & & \\
\hline
\end{tabular}

Table 4: Adverse effects of drug on patients.

\begin{tabular}{|c|c|c|c|c|c|}
\hline \multirow[t]{2}{*}{ Adverse effects } & \multicolumn{2}{|c|}{$\begin{array}{l}\text { Labetalol Group } \\
(n=100)\end{array}$} & \multicolumn{2}{|c|}{$\begin{array}{l}\text { Methyldopa Group } \\
(\mathrm{n}=\mathbf{1 0 0 )}\end{array}$} & \multirow[t]{2}{*}{ P value } \\
\hline & No & $\%$ & No & $\%$ & \\
\hline Nil & 88 & 88.0 & 82 & 82.0 & \multirow[b]{2}{*}{0.322} \\
\hline Present & 12 & 12.0 & 18 & 18.0 & \\
\hline $\begin{array}{l}\text { Minor side effects of Labetalol, Fatigue, } \\
\text { insomnia, bad dreams }\end{array}$ & 10 & 10 & & & \\
\hline $\begin{array}{l}\text { Serious side effects of Labetalol } \\
\text { Bronchospasm, blunted response to } \\
\text { hypoglycemia }\end{array}$ & 2 & 2 & & & \\
\hline $\begin{array}{l}\text { Adverse effects of methyldopa: } \\
\text { Postural hypotension, Sedation, depression, } \\
\text { Abnormal LFT, Salt and water retention }\end{array}$ & & & 18 & 18 & \\
\hline
\end{tabular}

Table 5: Pregnancy Complications.

\begin{tabular}{|c|c|c|c|c|c|}
\hline \multirow[t]{2}{*}{ Complications } & \multicolumn{2}{|c|}{$\begin{array}{l}\text { Labetalol Group } \\
(\mathrm{n}=100)\end{array}$} & \multicolumn{2}{|c|}{$\begin{array}{l}\text { Methyldopa Group } \\
(\mathrm{n}=100)\end{array}$} & \multirow[t]{2}{*}{ P value } \\
\hline & No & $\%$ & No & $\%$ & \\
\hline No Complication & 57 & $57 \%$ & 49 & $49 \%$ & \multirow[b]{2}{*}{$\mathrm{P}=0.322$} \\
\hline Present & 43 & $43 \%$ & 51 & $51 \%$ & \\
\hline $\begin{array}{l}\text { Progression of non proteinuric } \\
\text { Hypertensive Disorders of Pregnancy to: } \\
\text { Preeclampsia } \\
\text { Eclampsia }\end{array}$ & 22 & $22 \%$ & 26 & $26 \%$ & \\
\hline $\begin{array}{l}\text { Obstetric Complications: } \\
\text { Placental Abruption } \\
\text { Preterm labour } \\
\text { PPH }\end{array}$ & 28 & $28 \%$ & $33 \%$ & $33 \%$ & \\
\hline $\begin{array}{l}\text { Systemic complications: } \\
\text { Hepatic complication (HELLP Syndrome) } \\
\text { Renal complication } \\
\text { Cerebro-vascular accident }\end{array}$ & 3 & $3 \%$ & 5 & $5 \%$ & \\
\hline Maternal Mortality & 0 & $0 \%$ & 0 & $0 \%$ & \\
\hline
\end{tabular}


Table 6: Pregnancy Outcome.

\begin{tabular}{|c|c|c|c|c|c|}
\hline & \multicolumn{2}{|c|}{ Labetalol Group } & \multicolumn{2}{|c|}{ Methyldopa Group } & \multirow[t]{2}{*}{ P value } \\
\hline & No & $\%$ & No & $\%$ & \\
\hline \multicolumn{5}{|c|}{ Mode of onset of labour } & \multirow{4}{*}{0.252} \\
\hline Induced & 36 & $36 \%$ & 43 & $43 \%$ & \\
\hline Spontaneous & 39 & $39 \%$ & 31 & $31 \%$ & \\
\hline Total & 75 & $75 \%$ & 74 & $74 \%$ & \\
\hline \multicolumn{5}{|c|}{ Mode of Delivery } & \multirow{4}{*}{0.999} \\
\hline Vaginal & 52 & $52 \%$ & 51 & $51 \%$ & \\
\hline LSCS & 48 & $48 \%$ & 49 & $49 \%$ & \\
\hline Total & 100 & 100.0 & 100 & 100.0 & \\
\hline
\end{tabular}

Table 6 shows that $25 \%$ of patients in Labetalol group and $26 \%$ of patients in Methyldopa group were planned for elective caesarean section, and among remaining $75 \%$ of patients in Labetalol group, 39\% went into spontaneous labour and in $36 \%$ labour was induced. In Methyldopa group among $74 \%$ of patients, $31 \%$ went into spontaneous labour and in $43 \%$ labour was induced. Mode of onset of labour does not have statistically significant difference between two groups.

Mode of delivery shows that $48 \%$ of patients in Labetalol Group and $49 \%$ of patients in Methyldopa Group underwent Caesarean section, were as vaginal delivery was $52 \%$ in labetalol group and $51 \%$ in methyldopa group, without statistical significance difference between two groups.

\section{DISCUSSION}

Hypertensive disorders of pregnancy may complicate about $3-10 \%$ of all pregnancies with variable incidence among different hospitals and countries. ${ }^{8}$

It is one of the major causes of maternal morbidity and mortality leading to $10-15 \%$ of maternal deaths, especially in developing world. ${ }^{9}$

One of the main objectives in treating women with Hypertensive disorders of pregnancy with antihypertensive drugs is to prevent or delay progression to pre-eclampsia and other complication. Antihypertensive therapy is indicated for maternal benefit and also permits prolongation of the pregnancy and thereby improves fetal maturity. ${ }^{10}$

The first line drugs that can be used in Hypertensive disorders of pregnancy are Labetalol and Methyldopa.

The observations of present study shows that majority of the patients were Hindu (45\%) by religion, residing in rural area $(70 \%)$ and belong to medium socioeconomic state $(72 \%)$. Most of the patients studied up to graduation (49\%) and were married (99\%) and house wife (87\%). Hence, the patients residing in rural area with low income are predisposed to Hypertensive disorders of pregnancy in the present study.

Majority of patients in present study, between 20 to $24 \mathrm{yrs}$ (64\%), primiparous (48\%), between 33 to $37 \mathrm{wks}$ of gestation (85\%) and overweight (49\%) are at higher risk of developing Hypertensive disorders of pregnancy.

Risk of HDP decreases as the age and parity increases, were as risk increases with increased BMI and period of gestation. Increased risk of HDP in primiparity and young age group in present study is similar to findings of Sudarshan et al. ${ }^{11}$

Risk of Hypertensive disorders of pregnancy is maximum between 33-37 weeks of period of gestation and $49 \%$ of women had increased BMI i.e. $>25 \mathrm{Kgs} / \mathrm{m}^{2}$. In the present study, increased risk of Hypertensive disorders of pregnancy is observed in groups with BMI >25-30 $\mathrm{Kgs} / \mathrm{m}^{2}$ and $>30 \mathrm{Kgs} / \mathrm{m}^{2}$.

Significant reduction in systolic and diastolic BP with $\mathrm{p}$ value $<0.001$ after treatment is found in Labetalol group compared to Methyldopa group. This shows that labetalol is better drug in controlling BP in the present study.

Labetalol had less adverse effects with only $12 \%$ (out of 100 patients) of patients complaining of Fatigue, insomnia and bad dreams, whereas $18 \%$ of patients in Methyldopa group had various adverse effects of drug. This shows that labetalol is more compatible with better tolerance with less adverse effects in pregnancy.

Complications during pregnancy in patients treated with labetalol and methyldopa is documented. Some of the complications used to overlap in single patient. The overall rate of pregnancy complication due to Hypertensive disorders of pregnancy is less in labetalol group $(43 \%)$ in comparison to methyldopa group $(51 \%)$. Progression of Gestational Hypertension to preeclampsia/eclampsia is more in methyldopa group (26\%) than in labetalol group (22\%). Obstetric and systemic complications during pregnancy were less in labetalol group whereas it is more in Methyldopa group $(51 \%)$. No maternal mortality was seen in either group. 
Excluding the patients who were planned for elective caesarean section in both the groups, the need for 'induction of labour' (36\%) is less and 'spontaneous mode of onset of labour' (39\%) is more in Labetalol group. Also, labetalol group had more number of vaginal deliveries $(52 \%)$ and less number of caesarean section $(48 \%)$. Even though in Methyldopa group majority needed induction of labour $(43 \%)$ and increased rate of caesarean section $(49 \%)$ the difference is not statistically significant with Labetalol group.

\section{CONCLUSION}

The present study shows that primiparity, residing in rural area with low income group and overweight patients are at high risk of developing Hypertensive disorders of pregnancy.

Even though Labetalol is a better drug in controlling blood pressure with statistically significant difference, the lesser "adverse effects and maternal complication" is not significant statistically when compared with methyldopa. Also, spontaneous onset of labour and vaginal mode of delivery is more in patients taking labetalol, it does not have statistical significant difference with patients taking methyldopa.

\section{ACKNOWLEDGMENTS}

The authors are thankful to all the faculty and staff members of the Department of Obstetrics and Gynaecology, Regional Institute of Medical Sciences, Imphal, India and the patients for their immense cooperation and support during the study period.

Funding: No funding sources

Conflict of interest: None declared

Ethical approval: The study was approved by the Institutional Ethics Committee

\section{REFERENCES}

1. World health organization. Trend in maternal mortality: 1990 to 2008. Geneva: WHO, 2010. Available at http://whqlibdoc.who.int/publication/2010/97892415 00265_eng.pdf.
2. Sharma A, Poonam M, Bisht S. Management of pregnancy induced hypertension. IJRAP. 2010;1: 390-98.

3. Report of the National High Blood Pressure Education Program Working Group on High Blood Pressure in Pregnancy. Am J Obstet Gynecol. 2000;183:S1-22.

4. Arulkumaran S, Gopalan S, Kumar P. Obstetrics and Gynecology for Postgraduates. Universities Press 2009:271-89.

5. Begum F, Parveen T. Antihypertensive in hypertensive disorder of pregnancy. Bangladesh $\mathrm{J}$ Obstet Gynaecol. 2008;23;65-72.

6. FG Cunningham, KJ Leveno, SL Bloom, JC Hauth, DJ Rouse, CY Spong. Williams Obstetrics. McGraw Hill. $23^{\text {rd }}$ ed;706-7.

7. National Institute for Health and Care Excellence. Hypertension in Pregnancy: The Management of Hypertensive Disorders During Pregnancy. NICE clinical guideline 107. London: NICE; 2010.

8. Barron WM, Murphy MB, Lindheimer MD. In: Management of hypertension during pregnancy. $3^{\text {rd }}$ ed New York: Hypertension pathophysiology, diagnosis and management; 1990.2;1809-27.

9. Vigil-De Gracia P, Montufar-Rueda C, Ruiz J. Expectant management of severe preclampsia and preeclampsia superimposed on chronic hypertension between 24 and 34 weeks gestation. Eur J Obstet Gynecol Reprod Biol. 2003;107:24-7.

10. Podymow T, August P. Update on use of antihypertensive drugs in pregnancy. Am Heart Assoc J. 2007;51:960-69.

11. Sudarsan S, Ghosh RS, Ganguly RP, Das A: Comparative study on the efficacy of magnesium sulphate and diazepam in the management of eclampsia in a peripheral rural medical college (A cross over study of 440 cases). J Obstet Gynecol India. 2002;52:69-72.

Cite this article as: Harish KM, Shwetha N, Debnath D. Comparison of maternal outcome in patients treated with methyldopa and labetalol in the management of hypertensive disorders of pregnancy. Int J Reprod Contracept Obstet Gynecol 2018;7:2136-41. 